\title{
SIRT3 Facilitates Amniotic Fluid Stem Cells to Repair Diabetic Nephropathy Through Protecting Mitochondrial Homeostasis by Modulation of Mitophagy
}

\author{
Jianxun Feng Chang Lu Qin Dai Junqin Sheng Min Xu \\ Department of Nephrology, Xuhui District Central Hospital of Shanghai, Shanghai, China
}

\section{Key Words}

Amniotic fluid stem cells • Mitophagy $•$ SIRT3 $•$ Diabetic nephropathy

\begin{abstract}
Background/Aims: Amniotic fluid stem cells (AFSCs) transplantation is a promising therapeutic strategy for diabetic nephropathy. Sirtuin3 (SIRT3) is a novel mitochondrial protective factor. In the present study, we aimed to investigate whether SIRT3 protects against hyperglycemia-induced AFSCs damage and enhances the therapeutic efficiency of AFSCs in diabetic nephropathy. Methods: To establish the diabetic nephropathy model, db/ $\mathrm{db}$ mice were used. AFSCs were obtained and transplanted into the kidney tissue of $\mathrm{db} /$ $\mathrm{db}$ mice. Gain-of-function assay with SIRT3 overexpression was performed in AFSCs via adenoviral transfections (Ad/SIRT3). Cellular viability and apoptosis were measured via MTT, TUNEL assay and western blotting. Mitochondrial function was assessed via JC1 staining, mPTP opening assay, mitochondrial respiratory function analysis, and immunofluorescence analysis of cyt-c. Mitophagy was assessed via western blotting and immunofluorescence analysis. Renal histopathology and morphometric analysis were conducted via $\mathrm{H} \& \mathrm{E}$, Masson and PASM staining. Kidney function was detected via ELISA assay, western blotting and qPCR. Results: SIRT3 was downregulated in AFSCs under high glucose stimulation, where its expression was positively correlated with AFSCs survival and proliferation. Regaining SIRT3 activated mitophagy protecting AFSCs against high glucose-induced apoptosis via preserving mitochondrial function. Transplanting SIRT3-overexpressing AFSCs in db/db mice improved the abnormalities in glucose metabolic parameters, including the levels of glucose, insulin, C-peptide, HbAlc and inflammatory markers. In addition, the engraftment of SIRT3-modified AFSCs also reversed renal function, decreased renal hypertrophy, and ameliorated renal histological changes in $\mathrm{db} / \mathrm{db}$ mice. Functional studies confirmed that SIRT3-modified AFSCs promoted glomerulus survival and reduced renal fibrosis. Conclusion: Collectively, our results demonstrate that AFSCs may be a promising therapeutic treatment for ameliorating diabetes and the development of diabetic nephropathy and that the overexpression of SIRT3 in AFSCs may further increase the efficiency of stem cell-based therapy.




\section{Cellular Physiology Cell Physiol Biochem 2018;46:1508-1524 \\ \begin{tabular}{ll|l} 
and Biochemistry Published onlIne: April 24, 2018 & $\begin{array}{l}\text { (C) } 2018 \text { The Author(s). Published by S. Karger AG, Basel } \\
\text { www.karger.com/cpb }\end{array}$
\end{tabular}}

Feng et al.: SIRT3 Regulates Diabetic Nephropathy via AFSCs

\section{Introduction}

Over the last few decades, type 2 diabetes mellitus (T2DM) has been a leading cause of death worldwide. Notably, it has been proposed that $40 \%$ of T2DM patients may develop diabetic nephropathy (DN), which is a major cause of end-stage renal disease (ESRD) [1]. The hallmarks of DN includes glomerular cell apoptosis due to high glucose-induced stress and renal interstitial fibrosis due to the accumulation of extracellular matrix (ECM), which contribute to the irreversible decline in renal function [2,3]. Unfortunately, the molecular mechanisms underlying DN development are still unclear, and thus, no effective drugs are available to control DN. Recently, stem cell transplantation-based therapy has emerged as a novel therapeutic strategy for DN $[4,5]$. This regenerative medicine offers a new method for replenishing damaged cells and promoting the recovery of renal function via differentiation into glomeruli or the activation of paracrine cytokine signaling [6, 7]. Recent data have shown that bone marrow mesenchymal stem cell treatment may ameliorate the development of DN in a rodent model [8]. However, adult bone marrow stem cells are difficult to obtain and have a more restricted differentiation potential and a shorter life span than amniotic fluid stem cells (AFSCs), which is disadvantageous. Previous studies have demonstrated that AFSCs engraftment repairs lung injury [9], reduces cerebral ischemia damage [10], inhibits non-small cell lung carcinoma growth [11], alleviates acute kidney damage [12], protects $\beta$-cells against high glucose-induced stress [13], attenuates oxidative stress after kidney engraftment [14], and slows the development of heart failure [15]. For DN, although both animal and clinical studies have provided information that suggests stem cell transplantation improves renal function through possible glomerular formation and/or angiogenesis, few studies have investigated the effects of AFSC treatment on DN progression.

In addition, the major dilemma in stem cell therapy for DN is the low survival of transplanted cells in response to high glucose-induced stress [16,17]. Endogenous factors, such as inflammatory and immune responses, may contribute to cell death via excessive oxidative stress and mitochondrial damage. Thus, improving the resistance of grafted cells to oxidative stress and increasing cellular survival are critical for enhancing the efficacy of stem cell therapy. In oxidative stress-mediated cellular apoptosis, mitochondria have been documented to transmit apoptotic signals through the release of cytochrome c (cyt-c) into cytoplasm $[18,19]$. Recently, several researchers have demonstrated that mitochondria use mitophagy, a mitochondrial autophagy system [20], to remove damaged mitochondria and inhibit mitochondrial apoptosis $[21,22]$. However, whether mitophagy contributes to stem cell survival is unclear.

Several researchers have found that Sirtuin3 (SIRT3) is a pro-survival factor in stem cells $[23,24]$. Interestingly, SIRT3 is also a regulator of mitophagy. Based on this information, we wondered whether modulating SIRT3 may enhance stem cell survival after engraftment via modifying mitophagy $[25,26]$. Accordingly, the present study was designed to evaluate the possible effect of SIRT3-modified AFSCs on the development of DN. The results demonstrated that SIRT3 protected AFSCs against high glucose-induced apoptosis via the preservation of mitochondrial homeostasis by activating mitophagy. Subsequently, the transplantation of SIRT3-overexpressing AFSCs attenuated the glucose metabolic abnormalities and ameliorated the renal structural and functional injuries via promoting glomerulus survival and reducing renal fibrosis.

\section{Materials and Methods}

\section{Chemical reagents}

Levels of creatinine and blood urea nitrogen (BUN) were determined using a Cobas ® C311 Autoanalyzer (Roche Diagnostics, Indianapolis, USA) as per the manufacturer's protocols. Urinary albumin concentration was determined using an ELISA kit obtained from Bio-Medical Assays (Beijing, China). Levels of insulin, glucagon, C-Peptide, TNFa, MCP-1, laminin, precollagen III and IL-6 were determined using 


\section{Cellular Physiology Cell Physiol Biochem 2018;46:1508-1524 \begin{tabular}{l|l} 
and Biochemistry Published onlıne: April 24, 2018 & $\begin{array}{l}\text { (c) } 2018 \text { The Author(s). Published by S. Karger AG, Basel } \\
\text { www.karger.com/cpb }\end{array}$ \\
\hline
\end{tabular}}

Feng et al.: SIRT3 Regulates Diabetic Nephropathy via AFSCs

ELISA kits obtained from Cusabio Technology (Wuhan, China). The lipid hydroperoxides (LPOs) in kidney homogenates were determined using a LPO assay kit (Cayman Chemical, USA). The urinary isoprostane activity kit was purchased from Wanleibio (Wanlei, Shenyang, China). Tissue triglycerides and cholesterol kit was obtained from KEYGEN Biotech. Co., Ltd. (Nanjing, China). The Bicinchoninic Acid (BCA) Protein Assay Kit was purchased from Beyotime Institute of Biotechnology (Jiangsu, China). Tris, sodium dodecyl sulfate (SDS), and 4, 6-diamidino-2-phenylindole (DAPI) were purchased from Sigma (St. Louis, MO, USA).

\section{Isolation and characterization of AFSCs for transplantation}

AFSCs were obtained from amniotic fluid freshly collected by routine amniocentesis from healthy pregnant mice with a C57 background. Cells were cultured in StemPro MSC SFM (serum free medium, Thermo Fisher Scientific, Inc., cat.no. A1067501) supplemented with 10\% fetal bovine serum (Invitrogen, Carlsbad, CA, cat.no.12483020) and were incubated at $37^{\circ} \mathrm{C}$ with $5 \%$ carbon dioxide. Culture medium was changed every 3-4 days. For cellular identification, AFSCs at passage 3 were collected to assess surface antigens by flow cytometric analysis on a BD FACSCalibur flow cytometer. After being washed in PBS, AFSCs were incubated with the following anti-mouse monoclonal fluorescent antibodies at the concentrations recommended by the manufacturer for $30 \mathrm{~min}$ in the dark: FITC-labeled CD29, CD31, CD34, CD45, CD90 (BD Biosciences, USA) or IgG [27].

For adipogenic and osteogenic differentiation, StemPro ${ }^{\circledR}$ adipogenesis and osteogenesis differentiation media (Invitrogen Co., USA) were used according to the manufacturer's protocol. Cultures were refreshed every 2 to 3 days. After 3-4 weeks of culture, adipogenesis was assessed by incubating cells with Oil Red O solution to stain the neutral lipids in the cytoplasm [28]. Alizarin Red S (Sigma-Aldrich, USA) was used to evaluate osteogenic differentiation. To assess AFSC viability, normal glucose medium (5.5 mmol/L), mannitol medium (20 mmol/L mannitol + $5.5 \mathrm{mmol} / \mathrm{L}$ glucose, Sigma-Aldrich, USA) and high glucose medium (25 mmol/L) were used.

\section{Animals and treatment}

Male $\mathrm{db} / \mathrm{m}$ mice (wild type) and C57BL/KsJ db/db obese $(\mathrm{db} / \mathrm{db}$ ) mice were obtained from Jackson Laboratory (Bar Harbor, ME). Eight-week-old db/db mice were engrafted with AFSCs ( $1 \mathrm{~mL}$ of AFSCs, $3 \times 10^{6}$ cells $/ \mathrm{mL}$, was slowly injected into the mouse kidney). The mice were randomized into four groups ( $\mathrm{n}=$ 20 for each group, matched for weight): (i) wild type group (WT, db/m mice), (ii) control group (ctrl, db/ db mice), (iii) Ad-ctrl group (db/db mice + AFSCs transfected with control adenovirus group) and (iv) AdSIRT3 group (db/db mice + AFSCs transfected with SIRT3 adenovirus group). Before each local injection, the syringe was pushed backwards to confirm that the needle was not present inside the vessel. The animal experiments were performed for a 12-week period [29]. In the end, blood pressures were measured on conscious, acclimatized mice using the tail-cuff method. Blood samples were collected, and kidney tissues were harvested; one part of the kidney was snap-frozen in liquid nitrogen, and the other part was fixed with 10\% phosphate-buffered saline (PBS)-buffered formalin, processed, and embedded in paraffin [30].

\section{SIRT3 overexpression by adenovirus}

To carry out the gain-of-function assay with SIRT3, we overexpressed SIRT3 in AFSCs via adenovirusbased technology. First, the pCDH-mCMV-SIRT3 plasmid was purchased from Vigene Bioscience. Then, the plasmid was transfected into 293 T cells via Lipofectamine 2000 (Thermo Fisher Scientific, Inc., cat. no.11668019) for approximately $48-96 \mathrm{~h}$ in an incubator with $5 \% \mathrm{CO}_{2}$ at $37^{\circ} \mathrm{C}$ [31]. Subsequently, the supernatants were collected to obtain the adenovirus, which was identified via PCR. After amplification of the obtained SIRT3-adenovirus (Ad-SIRT3), the AFSCs were transfected with Ad/SIRT3 or Ad-control (Ad/ ctrl), and the overexpression efficiency was measured via western blotting.

\section{Sample preparation and histological analysis}

The kidneys were excised and rapidly frozen in Optimal Cutting Temperature medium at room temperature (Agar Scientific Ltd., Stansted, UK) for the preparation of frozen sections (4- $\mu$ m thickness). Hematoxylin-eosin staining, Masson trichrome staining and Periodic Schiff-Methenamine (PASM) staining were performed at room temperature and were observed with an inverted microscope (magnification, 40x; BX51; Olympus Corp., Tokyo, Japan) [32]. 


\section{Cellular Physiology Cell Physiol Biochem 2018;46:1508-1524 \begin{tabular}{ll|l} 
and Biochemistry & Dublished online: April 24, 2018 & $\begin{array}{l}\text { (c) } 2018 \text { The Author(s). Published by S. Karger AG, Basel } \\
\text { www.karger.com/cpb }\end{array}$
\end{tabular}}

\section{Immunofluorescence staining}

The samples were washed in PBS and permeabilized for $10 \mathrm{~min}$ at $4{ }^{\circ} \mathrm{C}$ in a solution of $0.1 \%$ Triton $\mathrm{X}-100$. Then, the samples were blocked with 10\% goat serum albumin (Invitrogen, USA) for $1 \mathrm{~h}$ at room temperature and subsequently incubated with primary antibodies overnight at $4^{\circ} \mathrm{C}$ [33]. After three rinses in PBS, secondary antibodies were added to the samples for $1 \mathrm{~h}$ at room temperature [34]. The following primary antibodies were used in this study: mitochondrial import receptor subunit Tom 20 homolog (Abcam, Cambridge, UK; cat. no. ab78547), lysosome-associated membrane glycoprotein 1 (Abcam; cat. no. ab24170), cytochrome-c (cyt-c; Abcam; cat. no. ab133504), and caspase-3 (Cell Signaling Technology, Inc.; cat. no. 9664). Images were observed with an inverted microscope (magnification, 40x; BX51; Olympus Corp., Tokyo, Japan).

\section{Western blotting}

Samples were lysed in RIPA buffer (Thermo Fisher Scientific, Inc., cat.no.89900) containing $1 \mathrm{mM}$ phenylmethylsulfonyl fluoride (PMSF, Thermo Fisher Scientific, Inc., cat.no.36978B). Subsequently, samples were centrifuged for approximately $10 \mathrm{~min}$ at $4{ }^{\circ} \mathrm{C}$, and the supernatant was collected. A mass of 40-60 $\mu \mathrm{g}$ proteins was loaded on a 12-15\% SDS-PAGE gel. Following electrophoresis, proteins were transferred to a polyvinylidene fluoride western blotting membrane (Roche Applied Science, Penzberg, Germany) [35]. Bands were detected using an enhanced chemiluminescence substrate (Applygen Technologies, Inc., Beijing, China). Band intensities were normalized to the respective internal standard signal intensity ( $\beta$-actin, 1:2, 000; Abcam; cat. no. ab8224] [36]. The experiment was repeated three times. The primaries antibodies used in the present study were against the following proteins: Pro-caspase3 (1:1, 000; Cell Signaling Technology, \#9662), cleaved caspase3 (1:1, 000; Cell Signaling Technology, \#9664), X-IAP (1:2, 000; Cell Signaling Technology, \#14334), caspase9 (1:1, 000; Abcam; \#ab32539), microtubule-associated protein light chain (LC)3II (1:1, 000; Cell Signaling Technology, \#3868), sequestome-1 (p62; 1:1, 000; Abcam; \#ab56416), Beclin1 (1:1, 000; Cell Signaling Technology, \#3495), autophagy protein 5 (Atg5; 1:1, 000; Cell Signaling Technology, \#12994), Sirt3 (1:1, 000; Cell Signaling Technology, \#2627), transforming growth factor (TGF) $\beta$ (1:1, 000; Cell Signaling Technology, \#3711), matrix metalloproteinase (MMP)9 (1:1, 000; Cell Signaling Technology, \#13667), collagen I (1:1, 000; Abcam, \#ab34710), collagen III (1:1, 000; Abcam, \#ab7778), collagen IV (1:1, 000; Abcam, \#ab19808) and Bax (1:1, 000; Abcam; \#ab32503).

Mitochondrial reactive oxygen species (mROS) detection, JC-1 staining and adenosine 5'-triphosphate (ATP) detection

Mitochondrial reactive oxygen species (mROS) measurements were conducted using the MitoSOX red mitochondrial superoxide indicator (Molecular Probes, USA). Mitochondrial potential was assessed using a JC-1 probe, a sensitive fluorescent dye used to detect alterations in mitochondrial potential [37]. Following treatment, cells were incubated with $10 \mathrm{mg} / \mathrm{ml} \mathrm{JC}-1$ for $10 \mathrm{~min}$ at $37^{\circ} \mathrm{C}$ in the dark and monitored with a fluorescence microscope (magnification, 100x; BX51; Olympus Corp., Tokyo, Japan) [38]. Redorange fluorescence was attributable to potential-dependent dye aggregation in the mitochondria. Green fluorescence, reflecting the monomeric form of JC-1, appeared in the cytosol following mitochondrial membrane depolarization [39].

The ATP level in cells was determined using an ATP Bioluminescence Assay kit (Beyotime, China) [40]. Cells were lysed with PBS lysis buffer (Sigma-Aldrich, St. Louis, MO, USA), followed by centrifugation at 10, $000 \mathrm{xg}$ for $2 \mathrm{~min}$ at $4^{\circ} \mathrm{C}$. The ATP level was determined by mixing $50 \mu \mathrm{l}$ of supernatant with $50 \mu \mathrm{l}$ of luciferase reagent, which catalyzed the light production from ATP and luciferin. The emitted light was measured using a microplate luminometer and was linearly compared with the ATP concentration [41].

\section{Mitochondrial respiratory function, mPTP opening measurement}

Mitochondrial respiratory function was measured polarographically at $30^{\circ} \mathrm{C}$ using a Biological Oxygen Monitor System [42] (Hansatech Instruments, King's Lynn, UK) and a Clark-type oxygen electrode (Hansatech DW1, Norfolk, UK). Mitochondrial respiration was initiated by adding glutamate and malate to the reaction mixture at a final concentration of 5 and $2.5 \mathrm{mmol} / \mathrm{L}$, respectively [43]. State 3 respiration was initiated by adding ADP (150 nmol/L); state 4 was measured as the rate of oxygen consumption after ADP phosphorylation. The mitochondrial respiratory function (state 3/state 4) was calculated as previously described [44]. 


\section{Cellular Physiology Cell Physiol Biochem 2018;46:1508-1524 \begin{tabular}{c|l} 
and Biochemistry Published on/Ine: April 24, 2018 & $\begin{array}{l}\text { C } 2018 \text { The Author(s). Published by S. Karger AG, Basel } \\
\text { www.karger.com/cpb }\end{array}$ \\
\hline
\end{tabular}}

Feng et al.: SIRT3 Regulates Diabetic Nephropathy via AFSCs

The MPTP opening assay was performed via the established calcein-cobalt loading procedure by incubating cells with calcein-acetoxymethyl ester (calcein-AM, Thermo Fisher Scientific, Inc., cat.no. C1430) according to a previous study. The immunofluorescence intensity of calcein-AM was measured as an indicator of mPTP opening [45].

\section{BrdU assay}

To evaluate cellular proliferation, the BrdU assay (RiboBio Co., Guangzhou, China) was used according to a previous study [46]. First, cells with or without SIRT3 overexpression were incubated with BrdU for approximately $2 \mathrm{~h}$ at room temperature. Then, the cells were fixed via $4 \%$ paraformaldehyde at $4{ }^{\circ} \mathrm{C}$, followed by permeabilization with $0.5 \%$ Triton X-100 for approximately $20 \mathrm{~min}$ at room temperature. At last, the cells were stained with DAPI (Sigma-Aldrich) for $5 \mathrm{~min}$ to distinguish the nuclei. Subsequently, the samples were viewed under a fluorescence microscope. Photos were captured, and the number of BrdU positive cells was measured via counting at least three random separate fields.

3-(4, 5-dimethylthiazol-2-yl)-2, 5-diphenyltetrazolium bromide (MTT), terminal deoxynucleotidyl transferase-mediated dUTP-biotin nick-end labeling (TUNEL) assay and caspase-9/3 activity detection

MTT experiments were performed in 96-well plates. Samples were washed 3 times with PBS, and 50 $\mu \mathrm{l}$ of MTT reagent (Sigma-Aldrich) was added to each well. The samples were subsequently incubated for $4 \mathrm{~h}$ at $37^{\circ} \mathrm{C}$ in a humid atmosphere containing $5 \% \mathrm{CO}_{2}$. The MTT solution was removed, $200 \mu \mathrm{l}$ of dimethyl sulfoxide was added to each sample, and the samples were incubated for $10 \mathrm{~min}$. Following the addition of Sorensen's buffer, the absorbance at a wavelength of $570 \mathrm{~nm}$ was determined. A TUNEL assay to detect DNA fragmentation in the cell nuclei (a marker for apoptosis in testicular tissue), was performed using an In Situ Cell Death Detection kit (Roche Diagnostics GmbH, Mannheim, Germany) according to the manufacturer's protocol. DAPI was used to label the nuclei (at room temperature for approximately $30 \mathrm{~min}$ ). Caspase-3/9 activity kits (Beyotime Institute of Biotechnology) were used according to the manufacturer's protocols. The relative caspase-3/9 activity levels were calculated from the ratio of treated cells to untreated cells. The assays were repeated three times.

\section{Measurement of biochemical parameters}

After $12 \mathrm{~h}$ of fasting, the blood glucose level of venous blood from the tail vein was measured using a glucometer (Roche, Mannheim, Germany). Blood and urine samples were collected. Kidney tissues were homogenized for further biochemical analysis [47]. Glycated hemoglobin (HbA1c) was measured using the in2it A1C system (Bio-Rad, Hercules, CA). The glutathione (GSH) and oxidized glutathione (GSSG) levels in the kidney were determined using commercial assay kits (Nanjing Jiancheng Company, Shanghai, China) [48].

To collect morning spot urine samples, animals were placed in metabolic cages at the beginning of the light cycle and were kept for $2 \mathrm{~h}$ with water but without food. To obtain the 24-h urine samples, animals were placed in metabolic cages at the beginning of the light cycle and were kept for $24 \mathrm{~h}$ with free access to water and a standard laboratory diet.

\section{RNA isolation qPCR analysis}

Total RNA was isolated from cells using TRIzol reagent (Invitrogen; Thermo Fisher Scientific, Inc.). A total of $1 \mu \mathrm{g}$ RNA from each sample was reverse-transcribed into cDNA using an RT kit (Eurogentec, Liege, Belgium) [46]. The qPCR was performed with primers and matched probes from the Universal Fluorescencelabeled Probe Library (Roche Diagnostics $\mathrm{GmbH}$ ) [49]. Quantification of gene expression was performed using an ABI PRISM 7500 Sequence Detection system (Applied Biosystems Life Technologies, Foster City, CA) with SYBR $®$ Green (TransGen Biotech Co., Ltd.). The relative mRNA expression levels were normalized to that of $\beta$-actin using the $2^{-\triangle \Delta \mathrm{CT}}$ method [50]. The experiments were repeated three times with triplicates.

\section{Statistical analysis}

All data are expressed as the mean \pm standard deviation. Statistical analyses were performed with SPSS software (version 17.0; SPSS, Inc., Chicago, IL, USA). Statistical significance between two groups was determined by Student's t-test. Results for more than two groups were evaluated by one-way analysis of variance with the least significant difference test. $\mathrm{P}<0.05$ was considered to indicate a statistically significant difference. 


\section{Results}

The identification of isolated AFSCs

As indicated in Fig. 1Aa, the majority of AFSCs in the third passage were adherent, in a fibrocyte-like form, and had a long shuttle shape. To ensure their multipotency, AFSCs were transdifferentiated into adipocytes, which was confirmed by Oil Red-0 staining; red oil drops were observed in the AFSCs (Fig. 1Ab). Similarly, AFSC osteogenesis was identified with Alizarin red staining of calcified nodules; red calcium nodules were identified after AFSCs differentiation (Fig. 1Ac). Third generation AFSCs were harvested, and the cell phenotypes were detected using flow cytometry. Most of the AFSCs expressed the specific stem cell markers CD29 and CD90 (Fig. 1B), which is consistent with the phenotypical characteristics of mesenchymal stem cells. In contrast, the AFSCs seldom expressed the hematopoietic markers CD34 and CD45. These cells were also negative for the expression of the vascular endothelial cell marker CD31.

High glucose reduces cellular viability and proliferation via the downregulation of SIRT3

Next, we investigated the role of SIRT3 in AFSCs viability under high glucose stimulation. First, our results showed that SIRT3 expression was progressively downregulated under high glucose treatment $(25 \mathrm{mM})$ in a time-dependent manner and that SIRT3 expression was lowest after $8 \mathrm{~h}$ of treatment with high glucose (Fig. 2A-B). Therefore, $25 \mathrm{mM}$ high glucose stimulation for $8 \mathrm{~h}$ was used in following experiments. To explain the causal role of SIRT3 in regulating AFSCs viability, we overexpressed SIRT3 in AFSCs using an adenovirusbased method (Ad/SIRT3). The transfection efficiency is shown in Fig. 2C. Meanwhile, the overexpression efficiency was confirmed by western blotting (Fig. 2D-E). Subsequently, the ability of SIRT3 to affect AFSCs viability and proliferation was tested. Meanwhile, to rule out the effect of osmolarity in cell culture studies, mannitol was also used as the control group. MTT assay results showed that Ad/SIRT3 significantly increased cellular viability under high glucose treatment (Fig. 2F). The change in caspase-3 activity (Fig. 2G) was also similar to the MTT assay results, suggesting that SIRT3 is vital for cell viability under high glucose-induced stress. Then, the CCK8 assay was used to detect cellular proliferation. The results indicated that high glucose alleviated AFSCs growth, and this change was reversed by Ad/SIRT3 (Fig. 2H). Subsequently, the BrdU incorporation assay was used to detect cell duplication. As shown in Fig. 2I-J, high glucose stimulation reduced the number of BrdU positive cells. However, the reintroduction of SIRT3 rescued the proliferative capacity of AFSCs after exposure to high glucose treatment.

\section{SIRT3 overexpression \\ promotes AFSC survival via blocking mitochondrial apoptosis \\ We further determined} the effect of SIRT3 on AFSC apoptosis under high glucoseinduced stress. TUNEL assays demonstrated that the number of TUNEL positive

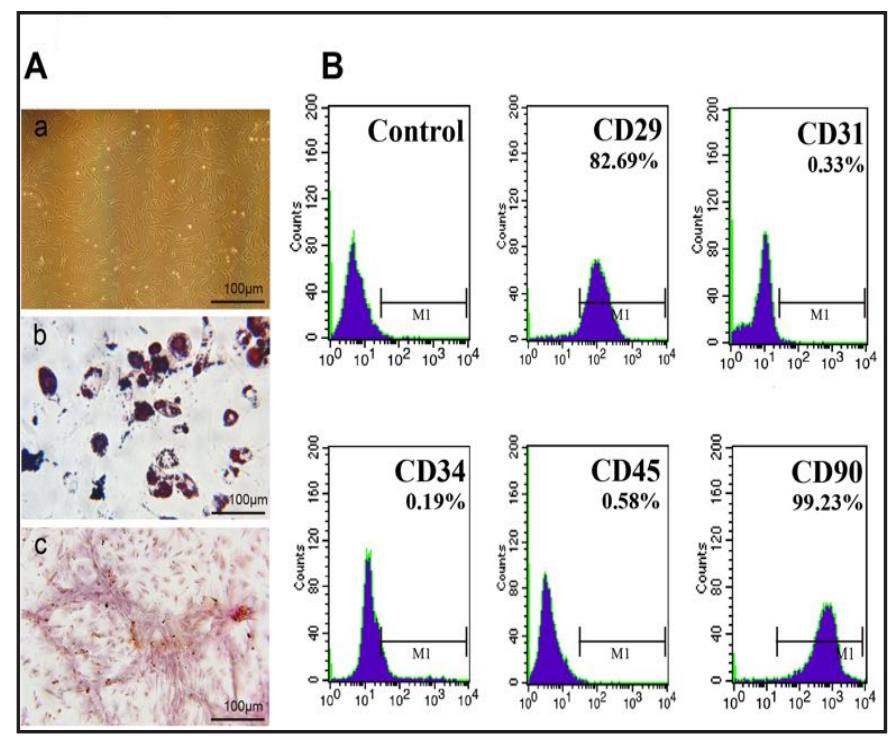

Fig. 1. The identification of AFSCs. A. (a) The morphology of AFSCs under a microscope. (b) The adipogenic differentiation of AFSCs, as detected by Oil Red-O staining. (c) The osteogenic differentiation of AFSCs, as detected by Alizarin Red staining. B. Flow cytometry results determining the AFSC phenotype. 
Fig. 2. SIRT3 is involved in AFSC viability and proliferation under high glucose stimulation. A-B. The change in the SIRT3 level in response to the high glucose treatment. C. The transfection efficiency of SIRT3 in AFSCs. D-E. The overexpression efficiency of SIRT3 in AFSCs was confirmed via western blotting. F. The MTT assay was used to detect cellular viability. G. Caspase-3 activity was measured to assess cellular apoptosis. H. The growth curve of AFSCs with SIRT3 overexpression (Ad/SIRT3) in response to high glucose stimulation. I-J. The BrdU assay was used to label proliferating cells. ${ }^{*} \mathrm{P}<0.05$ vs the ctrl + normal medium or Ad-ctrl + normal medium group, $\# \mathrm{P}<0.05$ vs the Ad-ctrl + high glucose group.

cells was decreased after SIRT3 transfection in response to high glucose-induced stress (Fig. 3A-B), suggesting that the overexpression of SIRT3 reduces AFSC apoptosis under

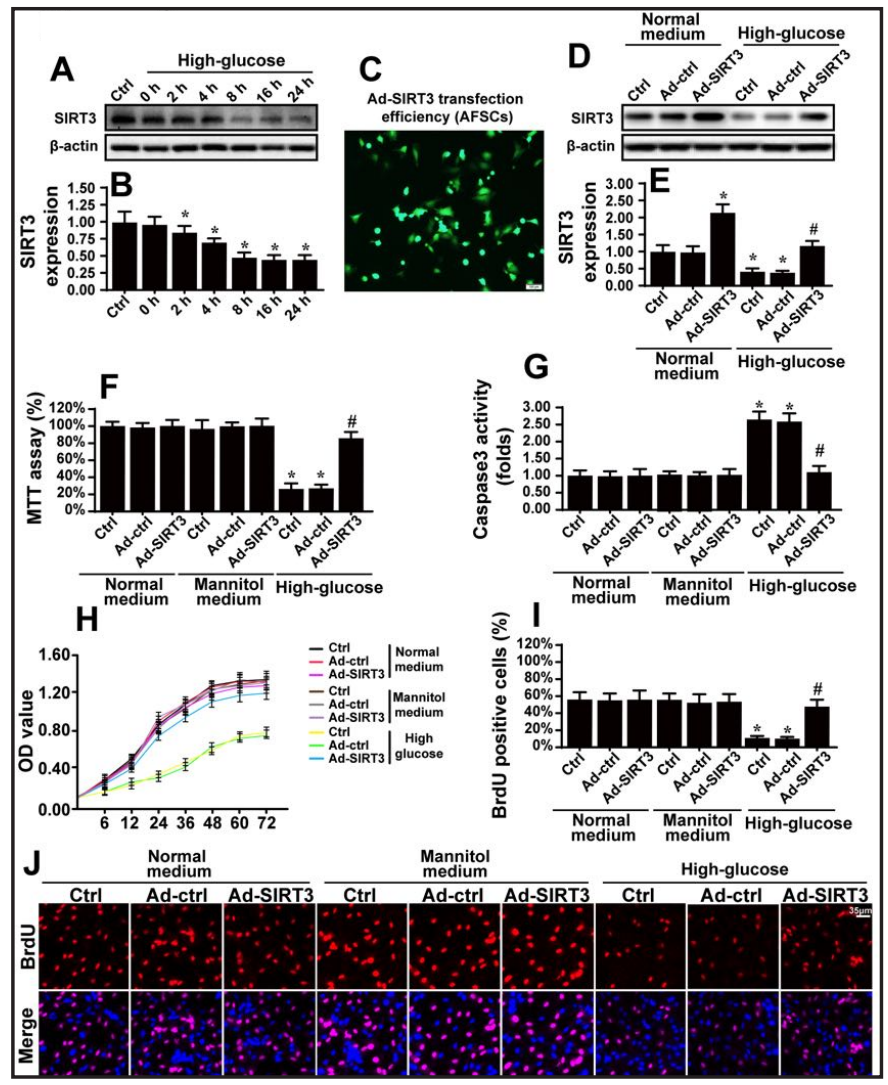
high glucose-induced stress. Considering that SIRT3 is a novel mitochondrial protective factor, we wondered whether the anti-apoptotic effect of SIRT3 results from mitochondrial protection. Compared to the control group, the SIRT3 overexpression group presented with sustained mitochondrial membrane potential (MMP), as evidenced by a higher red fluorescence and lower green fluorescence (Fig. 3C-D). The MMP is derived from the proton gradient [35]. Once the mitochondrial permeability transition pore (mPTP) is opened, protons are released into the cytoplasm, leading to MMP collapse. Therefore, we examined changes in the mPTP opening. High glucose increased the mPTP opening rate (Fig. 3E), and this change was reversed by Ad/SIRT3 after exposure to high glucose.

In addition, the opening of the MPTP establishes a channel that links the mitochondria and cytoplasm, promoting the leakage of the mitochondrial pro-apoptotic factor cyt-c from the mitochondria into the cytoplasm, where cyt-c has the ability to initiate mitochondrial apoptosis pathway [51]. Using immunofluorescence (Fig. 3F-G), we found that high glucose triggered cyt-c diffusion into the cytoplasm and even into the nucleus, and this change was recused by Ad/SIRT3 in the presence of high glucose. Next, as a consequence of cyt-c release into the cytoplasm, the expression levels of pro-apoptotic proteins were increased, whereas the levels of anti-apoptotic factors were reduced (Fig. 3H-L). However, SIRT3 overexpression corrected the imbalance between pro-apoptotic proteins and anti-apoptotic factors. Altogether, these data demonstrated that SIRT3 protected AFSCs against high glucoseinduced stress via maintaining mitochondrial function.

\section{SIRT3 activates mitophagy to sustain mitochondrial function and structure}

Mitophagy is vital for mitochondrial homeostasis [52]. In response to mitochondrial damage, mitochondria utilize the lysosome to degrade damaged mitochondria in order to sustain the quantity and quality of the mitochondrial mass [53]. We wondered whether mitophagy is involved in SIRT3-related mitochondrial protection. Through co-staining of the mitochondria and lysosome, we found that compared to the normal group, high glucose 
Fig. 3. SIRT3 overexpression protected AFSC mitochondrial function. To rule out the effect of osmolarity in cell culture studies, mannitol was also used as the control group. A-B. The TUNEL assay was used to detect cellular apoptosis. C-D. Changes in mitochondrial membrane potential were analyzed via JC-1 staining. Red fluorescence represents normal mitochondrial potential, whereas green fluorescence is indicative of a damaged mitochondrial poten-
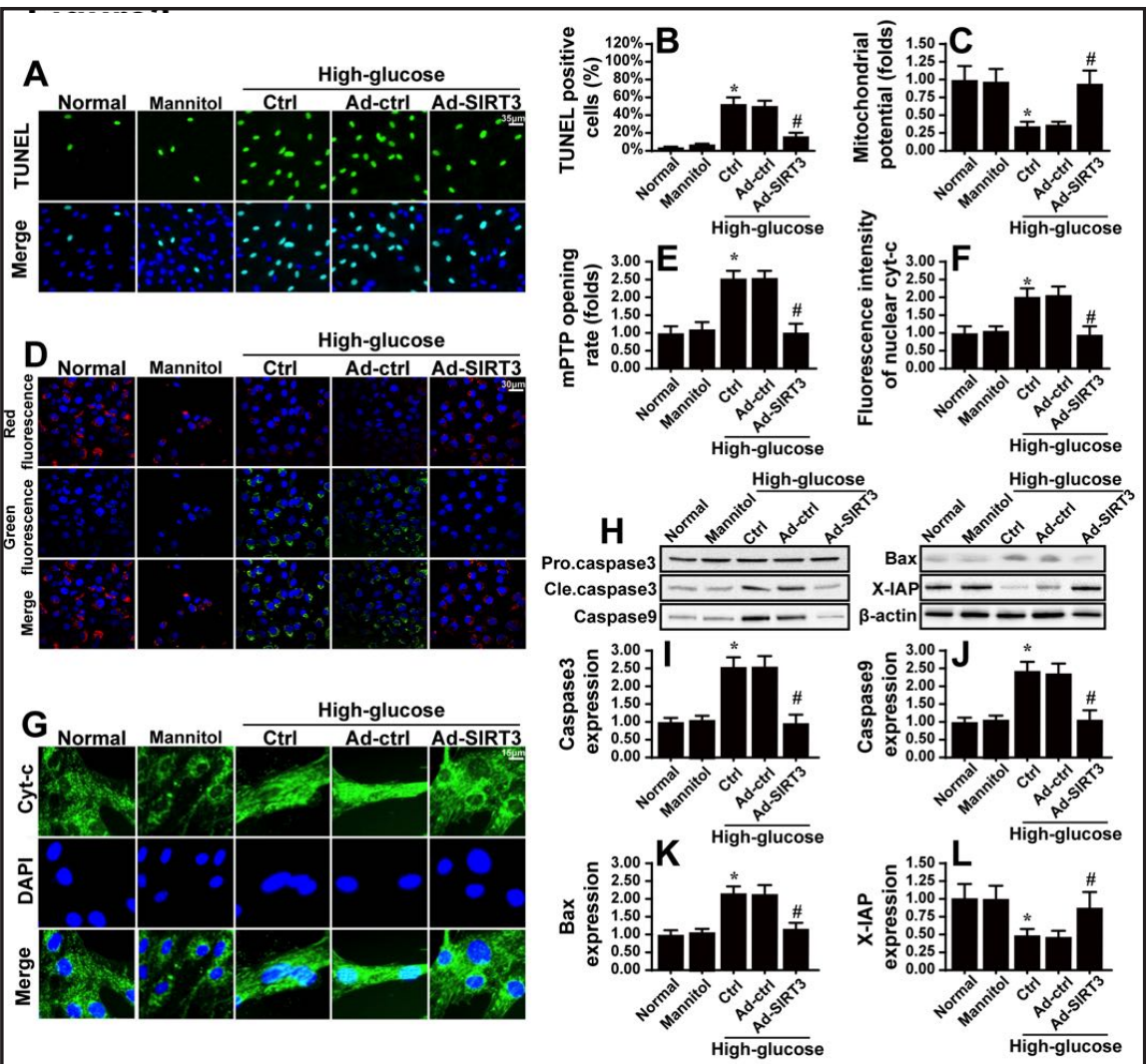

tial. E. The mPTP

opening rate. F-G. The staining of cyt-c in AFSCs. In response to mitochondrial damage, cyt-c is released from the mitochondria into the cytoplasm and even into the nuclei. H-L. Proteins were isolated from AFSCs, and then, western blotting was conducted to measure changes in the levels of proteins related to cellular apoptosis. ${ }^{*} \mathrm{P}<0.05$ vs the normal group, $\# \mathrm{P}<0.05$ vs the Ad-ctrl + high glucose group.

treatment promoted the mitochondria separation from lysosome (Fig. 4A). However, restoring SIRT3 caused fusion of the mitochondria and lysosome (Fig. 4A). These data indicated that mitophagy was actually inhibited by high glucose and that the reintroduction of SIRT3 reversed mitophagy activity. Next, to quantitatively detect mitophagy activity, western blotting was used to analyze the mitophagy markers. As shown in Fig. 4B-F, high glucose reduced the expression of mitochondrial LC3II (mito-LC3II), Beclin1 and Atg5. In contrast, p62 expression was increased. After transfection with SIRT3, mitophagy parameters including mito-LC3II, Beclin1 and Atg5 were increased, suggesting that mitophagy activity was enhanced by SIRT3 under high glucose-induced stress.

To further understand the role of mitophagy in mitochondrial protection, we detected caspase-3 activity. Meanwhile, we inhibited mitophagy activity via 3-MA in Ad/SIRT3treated AFSCs. As shown in Fig. 4G, compared to the Ad/SIRT3-treated AFSCs, the inhibition of mitophagy abrogated the anti-apoptotic effects of SIRT3. In addition to cellular apoptosis, we also observed the changes in mitochondrial function when mitophagy was inhibited. Compared to the Ad/SIRT3-treated cells, cells in which mitophagy was inhibited had reduced levels of ATP production (Fig. 4H). Moreover, the level of mitochondrial ROS (mROS) was actually decreased after SIRT3 overexpression but was re-increased once mitophagy was inhibited via 3-MA (Fig. 4I-J). Mitochondrial respiratory function (State 3/4 respiratory activity) was also reduced in cells with mitophagy inhibited compared to Ad/SIRT3-treated cells (Fig. 4K-L). In summary, these data indicated that SIRT3 protected AFSCs against high glucose-induced apoptosis via the preservation of mitochondrial function by mitophagy activation. 
Fig. 4. SIRT3 overexpression sustained mitochondrial function via activating mitophagy. A. Costaining of the mitochondria and lysosome. Orange fluorescence represents fusion of the mitochondria and lysosome, indicative of mitophagy. B-F. Changes in mitophagy-related parameters. G. Caspase-3 activity was used to detect the role of mitophagy in cellular apoptosis. 3-MA was used to inhibit mitophagy. H. ATP production was detected. I-J. Mitochondrial ROS (mROS) was observed via immunofluorescence. K-L. Mitochondrial respiratory function measurements via State 3 and State 4 respiratory function assessment. ${ }^{*} \mathrm{P}<0.05$ vs the normal group, $\# \mathrm{P}<0.05$ vs the Ad-ctrl + high glucose group, @ P $<0.05$ vs the Ad-SIRT3 + high glucose group.

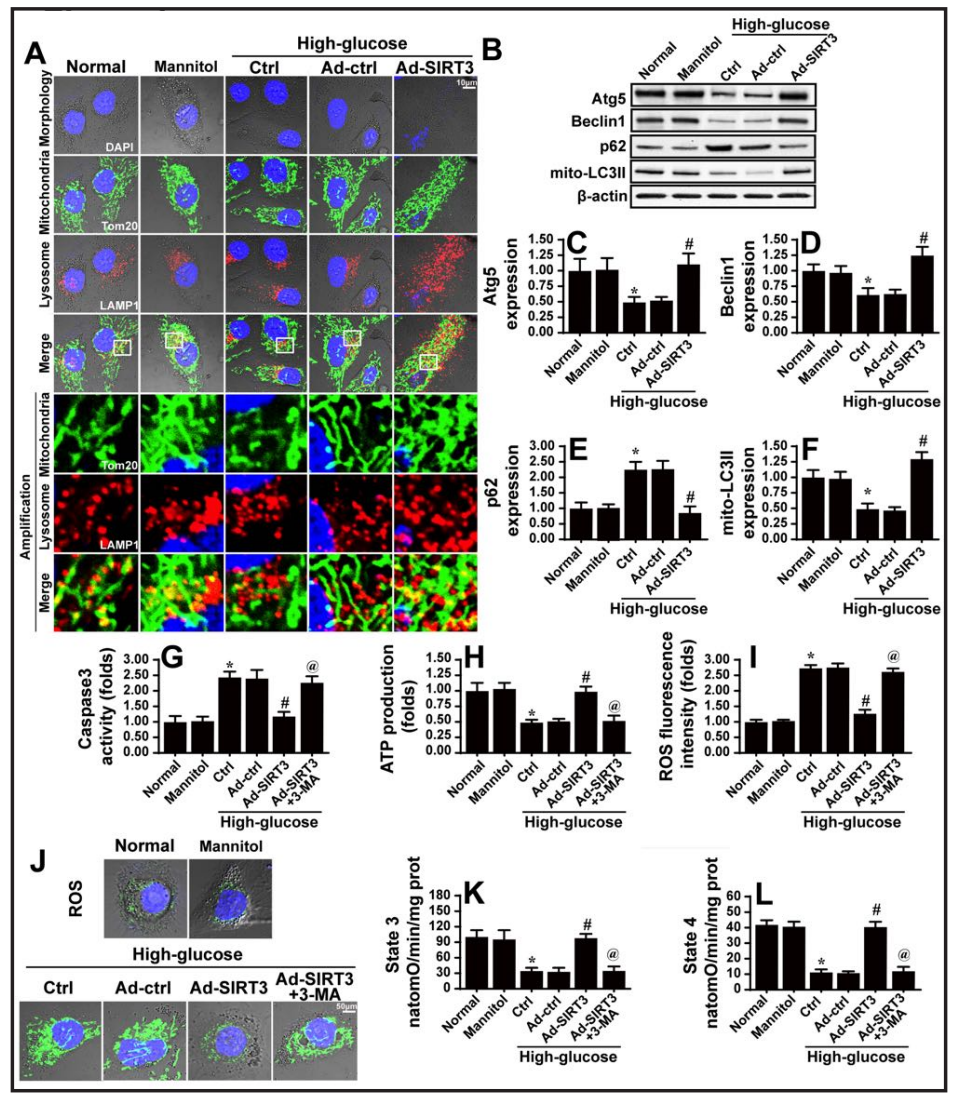

SIRT3 overexpression enhanced AFSC transplantation therapy in diabetes

We further explored the effects of SIRT3overexpressing AFSC engraftment on changes in kidney function in diabetes. The results in Fig. 5A show that, as expected, the body weights of the $\mathrm{db}$ / $\mathrm{db}$ mice were significantly higher than those of the wild-type mice, and the administration of AFSCs (Ad-ctrl group) significantly re-

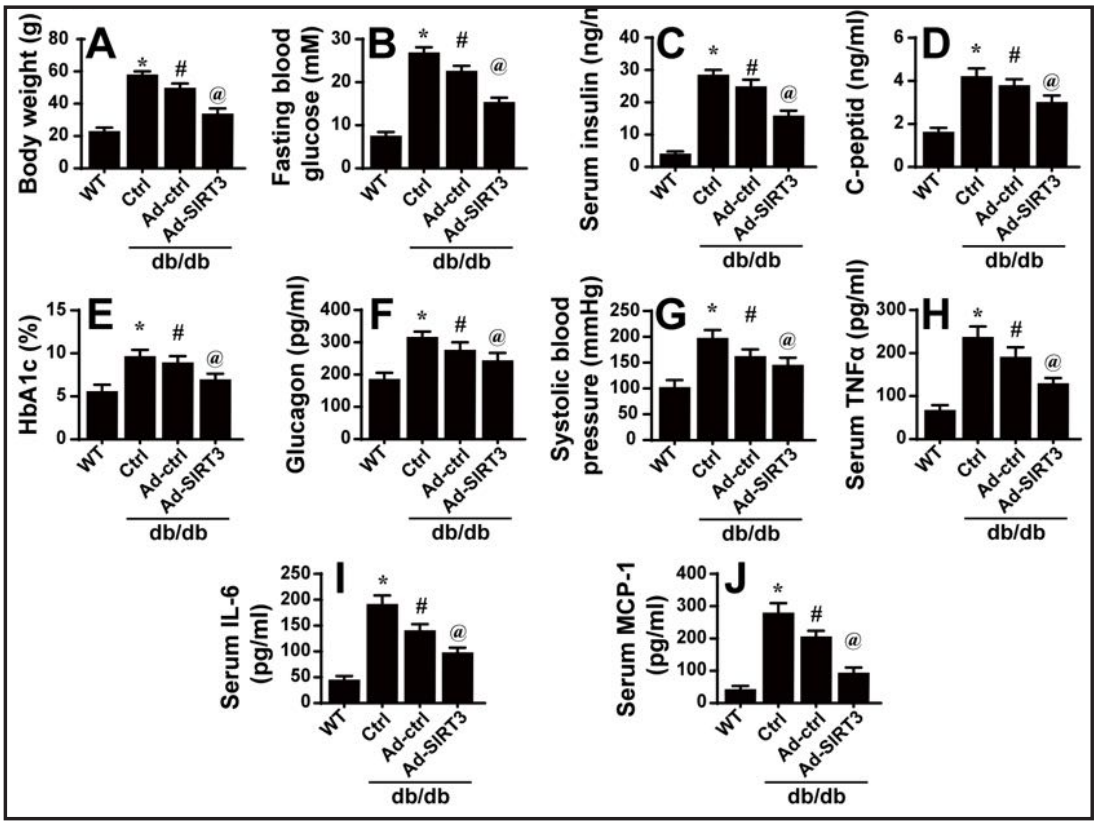

Fig. 5. Transplantation of SIRT3-overexpressing AFSCs attenuated glucose metabolic abnormalities in $\mathrm{db} / \mathrm{db}$ mice. Body weights (A) were measured, and fasting blood glucose (B), serum insulin (C), C-peptide (D), HbA1c (E) and glucagon (F) levels were determined. G. Systolic blood pressure was measured. H-J. The serum concentrations of IL6, MCP1 and TNF $\alpha$ were detected via ELISA assays. ${ }^{*} \mathrm{P}<0.05$ vs WT mice, \#P<0.05 vs the control group ( $\mathrm{db} / \mathrm{db}$ mice), @ $\mathrm{P}<0.05$ vs Ad-ctrl $+\mathrm{db} /$ $\mathrm{db}$ mice. 
duced the body weights of $\mathrm{db} /$ $\mathrm{db}$ mice. In addition, the Ad/ SIRT3-treated AFSCs (AdSIRT3 group) further reduced the body weights. The fasting blood glucose (Fig. 5B) and serum insulin (Fig. 5C) levels in the $\mathrm{db} /$ $\mathrm{db}$ mice were markedly higher than those of the wild-type mice, and AFSC e $\mathrm{ngraft}$ m en $\mathrm{t}$ (Ad-ctrl group) substantially decreased fasting blood glucose and serum insulin levels in $\mathrm{db} /$ db mice. Notably, Ad/SIRT3-treated AFSCs (AdSIRT3 group) further reduced

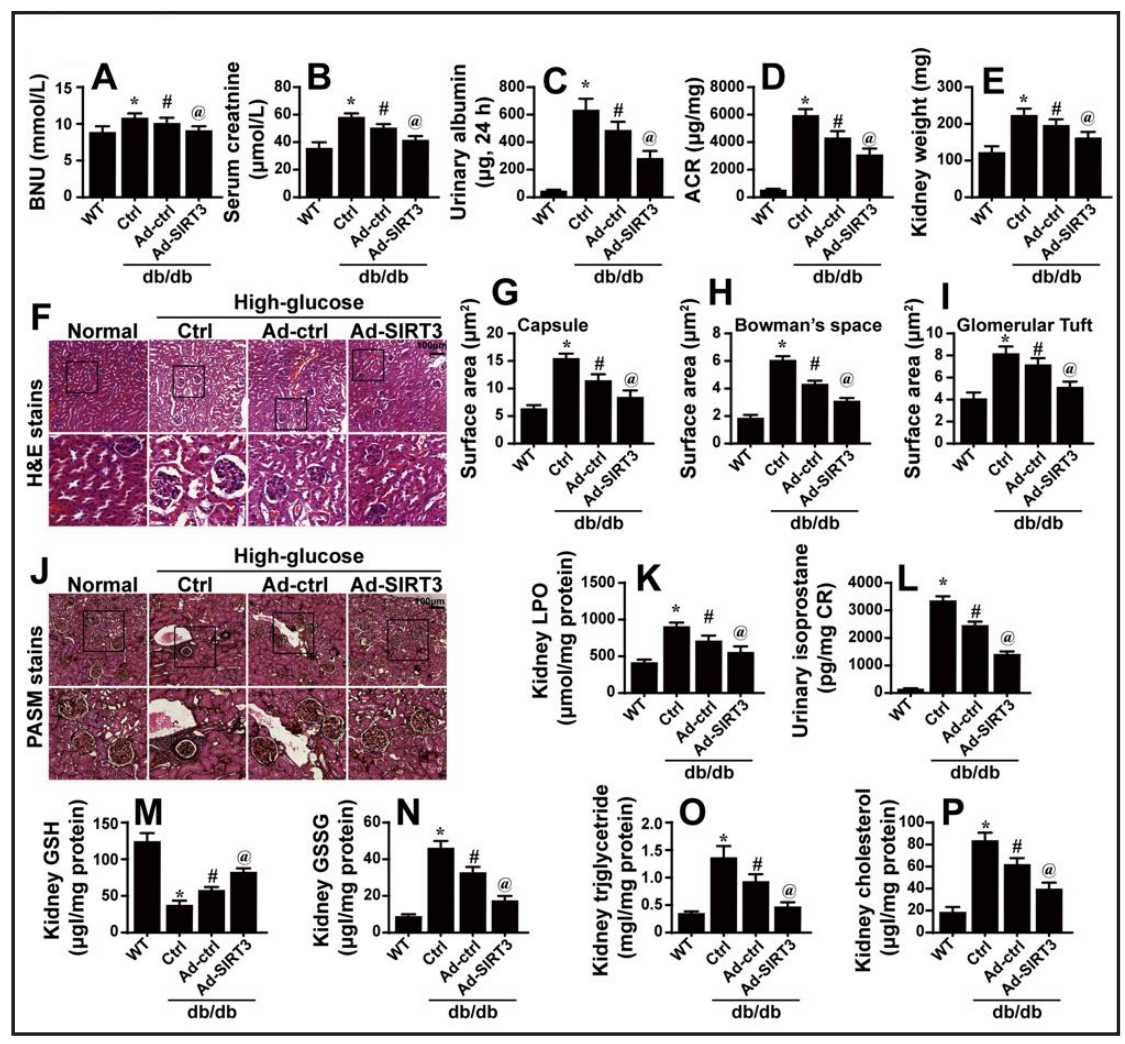

Fig. 6. Transplantation of SIRT3-overexpressing AFSCs attenuated renal injury in $\mathrm{db} / \mathrm{db}$ mice. A. BUN level. B. Serum creatinine level. C. Urinary albumin content. D. ACR level. E. Kidney weights. F. H\&E stains of kidney sections. G. Surface areas of Bowman's capsule. H. Bowman's space. I. Glomerular tuft. J. PASM staining of kidney tissues. K-N. Oxidative stress markers were examined in the kidney. O-P. Lipid accumulation in the kidney was evaluated. ${ }^{*} \mathrm{P}<0.05$ vs WT mice, $\# \mathrm{P}<0.05$ vs the control group (db/db mice), @ $\mathrm{P}<0.05$ vs Ad-ctrl $+\mathrm{db} / \mathrm{db}$ mice.

the fasting blood glucose and se-

rum insulin levels compared to the effect of Ad/ctrl-treated AFSCs (Fig. 5B-C). Moreover, the levels of serum C-peptide (Fig. 5D) and glycosylated hemoglobin A1c (HbA1c, Fig. 5E) in the $\mathrm{db} / \mathrm{db}$ mice were markedly higher than those in the wild-type mice. The administration of AFSCs significantly reduced the levels of serum C-peptide and HbA1c in $\mathrm{db} / \mathrm{db}$ mice. However, Ad/SIRT3-treated AFSCs exerted a greater inhibitory effect on serum C-peptide and $\mathrm{HbA1c}$ levels than that induced by Ad/ctrl-treated AFSCs. In addition, the high level of glucagon in the $\mathrm{db} / \mathrm{db}$ mice was alleviated by AFSC transplantation (Fig. 5F), and this effect was enhanced by Ad/SIRT3-treated AFSCs.

In addition, the increased systolic blood pressure of the $\mathrm{db} / \mathrm{db}$ mice was also inhibited by AFSCs in a SIRT3-dependent manner (Fig. 5G). Furthermore, during the development of diabetes, inflammatory marker levels are increased in the $\mathrm{db} / \mathrm{db}$ mice compared to those in the wild-type mice (Fig. 5H-I). AFSC administration markedly reduced the levels of these cytokines in the $\mathrm{db} / \mathrm{db}$ mice, and this effect was enhanced by SIRT3 overexpression. In summary, these data illustrated that AFSC engraftment exhibited an anti-diabetic effect, which was improved by SIRT3 overexpression.

SIRT3-overexpressing AFSCs ameliorate renal structural and functional injury in diabetes

Renal function was evaluated by the determination of the blood urea nitrogen (BUN) (Fig. 6A) and serum creatinine (Fig. 6B) levels at the end of the experiment. We revealed that the levels of BUN and serum creatinine in the $\mathrm{db} / \mathrm{db}$ mice were markedly higher than those 
Fig. 7. SIRT3-modified AFSC engraftment reduced glomerular apoptosis. A-B. The expression of caspase- 3 in kidney tissue. C. The change in caspase-3 activity. D-H. Western blotting was used to detect changes in the levels of apoptosisrelated proteins. I-L. qPCR assays were used to analyze the transcription of apoptosis-associated genes. $* \mathrm{P}<0.05$ vs WT mice, $\# \mathrm{P}<0.05$ vs the control group (db/db mice), @ $\mathrm{P}<0.05$ vs Ad-ctrl $+\mathrm{db} /$ $\mathrm{db}$ mice.
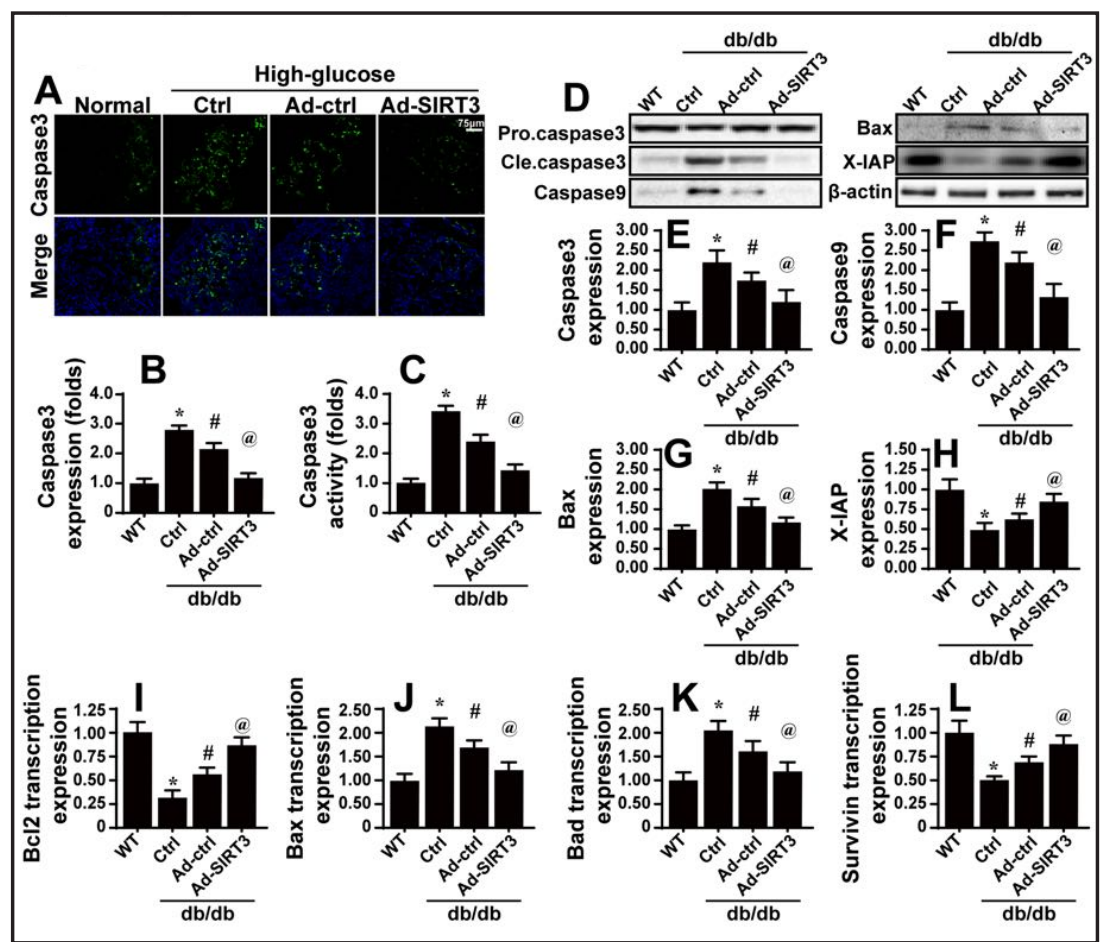

in the wild-type mice (Fig. 6A-B). AFSC transplantation (Ad-ctrl group) significantly reduced the levels of BUN and serum creatinine in the $\mathrm{db} / \mathrm{db}$ mice. Notably, Ad/SIRT3-treated AFSCs (Ad-SIRT3 group) were able to further decrease the BUN and creatinine levels. Additionally, the urinary albumin content and albumin/creatinine ratio (ACR) were measured to evaluate the progression of diabetic nephropathy. As shown in Fig. 6C and D, compared with the wildtype mice, the $\mathrm{db} / \mathrm{db}$ mice exhibited a significantly higher urinary albumin content level and ACR. The transplantation of AFSCs markedly reduced the urinary albumin content level and ACR in the $\mathrm{db} / \mathrm{db}$ mice, and this protective effect was enhanced by SIRT3 overexpression.

To evaluate renal hypertrophy, the kidneys were weighed after the mice were sacrificed. The absolute kidney weights were significantly higher in the $\mathrm{db} / \mathrm{db}$ mice than in the wildtype mice (Fig. 6E). AFSCs transplantation resulted in a marked decrease in kidney weight in the db/db mice (Fig. 6E). Notably, SIRT3-overexpressing AFSCs further reduced the kidney weights. These results were supported by the histopathological examination of H\&E- and PASM-stained kidney tissues (Fig. 6F-J). The histopathological results showed that the $\mathrm{db} / \mathrm{db}$ mice exhibited moderate of glomeruli atrophy and fragmentation, epithelial desquamation, renal tubule degeneration (Fig. 6F-I) and kidney glomerular basement membrane thickening (Fig. 6J). However, these renal histopathological changes in the $\mathrm{db} / \mathrm{db}$ mice were attenuated by AFSCs treatment (Ad-ctrl group). Notably, the Ad/SIRT3-treated AFSCs (Ad-SIRT3 group) further improved the renal structure.

The effect of AFSCs on kidney oxidative stress in mice was evaluated in this study. We showed that the levels of renal cortical tissue lipid hydroperoxides (LPO) and urinary 8-isoprostane were notably higher in the $\mathrm{db} / \mathrm{db}$ mice than in the wild-type mice (Fig. 6K-L). AFSC administration markedly reduced the renal LPO and urinary 8-isoprostane content in the $\mathrm{db} / \mathrm{db}$ mice (Fig. 6K-L). These effects were enhanced by SIRT3 overexpression in AFSCs. In addition, the content of glutathione (GSH) in the renal cortical tissue of the $\mathrm{db} / \mathrm{db}$ mice was notably lower than that of the wild-type mice (Fig. 6M). AFSCs administration increased the renal level of GSH in the db/db mice (Fig. 6M), while the content of GSSG (oxidized form of GSH) in the renal cortical tissue of the $\mathrm{db} / \mathrm{db}$ mice was notably higher than that of the wild-type mice (Fig. $6 \mathrm{~N}$ ). The high level of renal GSSG in the $\mathrm{db} / \mathrm{db}$ mice was reduced by AFSCs administration in a SIRT3-dependent manner (Fig. 6N). 
Fig. 8. Transplantation of SIRT3-overexpressing AFSCs reduces renal fibrosis. A. Masson staining for kidney fibrosis. B-G. Western blotting was used to detect changes in the levels of proteins related to renal fibrosis. H-I. The serum concentration of laminin and precollagen III via ELISA assay. ${ }^{*} \mathrm{P}<0.05$ vs WT mice, $\# \mathrm{P}<0.05$ vs the control group (db/db mice), @ $\mathrm{P}<0.05$ vs Ad-ctrl + db/db mice.

Finally, lipid accumulation in the kidney tissues was measured in the animals. We revealed that the renal concentrations of triglycerides (Fig. 60)
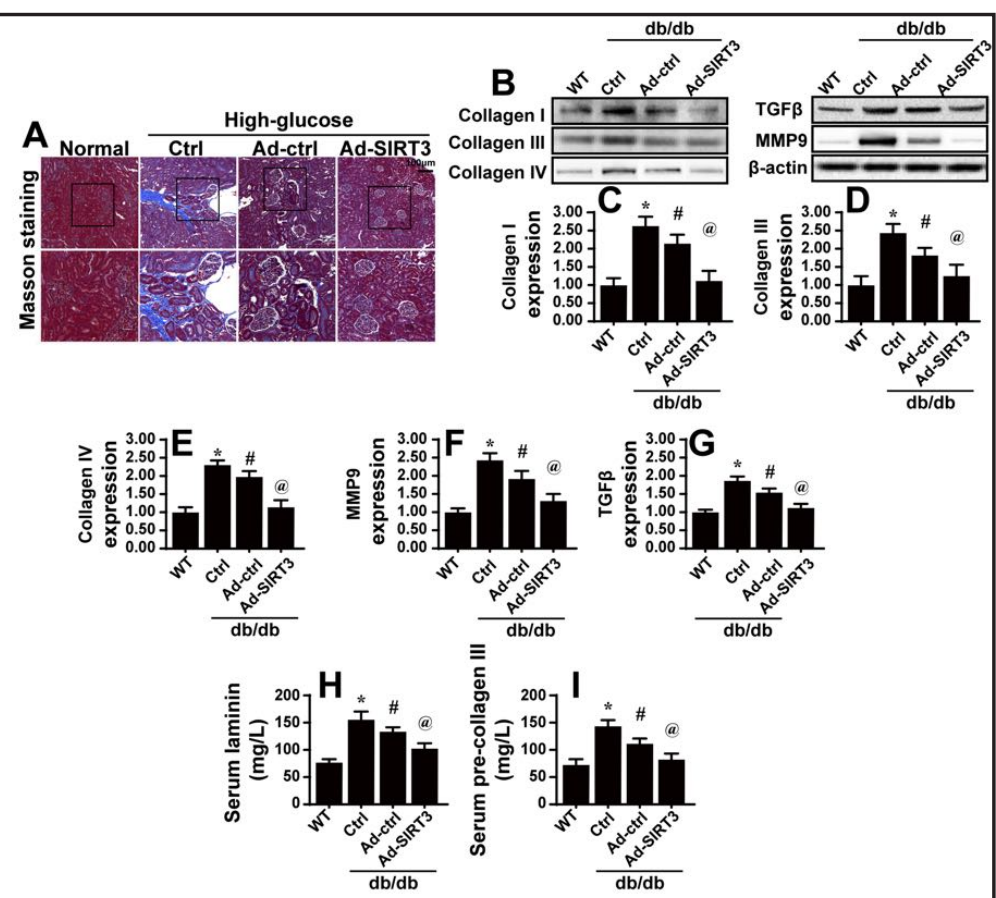

and cholesterol (Fig. 6P)

were notably higher in the $\mathrm{db} / \mathrm{db}$ mice than in the wild-type mice. As expected, the high levels of renal triglycerides and cholesterol were reduced by AFSCs, and this effect was enhanced by SIRT3 overexpression. These results indicated that AFSCs protected against renal dysfunction in $\mathrm{db} / \mathrm{db}$ mice, and the overexpression of SIRT3 in AFSCs further enhanced the therapeutic effect of AFSCs on DN.

\section{SIRT3-overexpressing AFSCs promote glomerulus survival}

Glomerular apoptosis is the primary factor involved in the development of DN. Therefore, we measured the role of SIRT3-modified AFSCs in glomerular apoptosis. First, caspase-3 staining demonstrated that the renal tissue in $\mathrm{db} / \mathrm{db}$ mice had increased cleaved caspase- 3 expression compared to that in the wild-type mice (Fig. 7A-B). However, AFSC engraftment (Ad-ctrl group) reduced caspase-3 expression, and this effect was enhanced by SIRT3 overexpression (Ad-SIRT3 group). Similar results were obtained in caspase- 3 activity assays (Fig. 7C). Moreover, to further investigate the protective effects of AFSC transplantation in glomerular apoptosis, western blotting was used. AFSC engraftment reduced the expression of pro-apoptotic proteins but increased the content of anti-apoptotic factors in a SIRT3dependent manner (Fig. 7D-H). In addition, we also measured the changes in the levels of apoptosis-related genes. The results showed that the mRNA expression levels of $\mathrm{Bcl} 2$ and survivin were significantly lower in the kidney tissues of $\mathrm{db} / \mathrm{db}$ mice than in the kidneys of the wild-type mice. In contrast, the transcription of p53 and Bad was increased in $\mathrm{db} /$ $\mathrm{db}$ mice compared to wild-type mice. Treatment with AFSCs markedly reduced Bad/p53 transcription and reversed Bcl2/survivin mRNA expression in the $\mathrm{db} / \mathrm{db}$ mice in a SIRT3dependent manner (Fig. 7I-L).

\section{Transplantation of SIRT3-overexpressing AFSCs reduces renal fibrosis}

Subsequently, we observed renal fibrosis via Masson staining. As shown in Fig. 8A, compared to the WT mice, the $\mathrm{db} / \mathrm{db}$ mice presented with severe kidney fibrosis, and this change was partly reversed by AFSC engraftment. When SIRT3 was overexpressed in AFSCs, renal fibrosis was further suppressed. In addition, the expression levels of collagen I, collagen III and collagen IV in the kidneys were assessed. Chronic hyperglycemia increased the expression of collagen I, collagen III and collagen IV, which was partly inhibited by AFSCs 


\section{Cellular Physiology Cell Physiol Biochem 2018;46:1508-1524 \\ and Biochemistry Published online: April 24, $2018 \quad \begin{aligned} & \text { DOI 10.159/B } 2018 \text { The Author(s). Published by S. Karger AG, Basel } \\ & \text { www.karger.com/cpb }\end{aligned}$ \\ Feng et al.: SIRT3 Regulates Diabetic Nephropathy via AFSCs}

in a SIRT3-dependent manner (Fig. 8B-E). Notably, the signaling factors related to fibrosis including TGF $\beta$ and MMP9 were also higher in the kidney tissues of $\mathrm{db} / \mathrm{db}$ mice than in those of the wild-type mice (Fig. 8F-G). Treatment with AFSCs markedly reduced the TGF $\beta$ and MMP9 expression levels in the $\mathrm{db} / \mathrm{db}$ mice, and this effect was enhanced by SIRT3 overexpression.

At last, the serum concentrations of laminin (Fig. 8H) and precollagen III (Fig. 8I) were notably higher in the $\mathrm{db} / \mathrm{db}$ mice than in the wild-type mice. As expected, the high serum concentration of laminin and precollagen III was reduced by AFSC transplantation, and this effect was enhanced by SIRT3 overexpression. These results indicated that AFSCs regulated renal interstitial fibrosis, and SIRT3-modified AFSCs have a better anti-fibrotic effect than normal AFSCs.

\section{Discussion}

In the current study, we investigated a method for improving the therapeutic efficiency of AFSCs engraftment in kidney tissue by overexpressing SIRT3 in the context of diabetes. We found that SIRT3-modified AFSCs engraftment exerted a more potent protective effect against diabetic nephropathy progression than that of normal AFSCs transplantation. The engraftment of SIRT3-modified AFSCs improved the abnormal changes in glucose metabolic parameters, including the levels of glucose, insulin, C-peptide, and HbA1c, and in the blood pressure of $\mathrm{db} / \mathrm{db}$ mice. In addition, the engraftment of SIRT3-modified AFSCs further improved renal function, decreased renal hypertrophy, and ameliorated the renal histological changes observed in $\mathrm{db} / \mathrm{db}$ mice. These beneficial effects may be resulted from the antiapoptotic and anti-fibrotic activities of SIRT3-modified AFSCs. Notably, due to technical complications, we were unable to detect changes in the survival rate of SIRT3-modified AFSCs after transplantation. Although we observed the protective role of AFSCs engraftment in diabetic nephropathy, we cannot detect the survival rate of AFSCs after engraftment. Therefore, more researches are needed in the further to answer this question.

Diabetic nephropathy is one of the most common and severe microvascular complications in patients with diabetes mellitus and is the leading cause of end-stage renal disease (ESRD). Furthermore, approximately $50 \%$ of patients with DN develop ESRD [1]. DN is pathologically characterized by mesangial dilatation, glomerulosclerosis and renal interstitial fibrosis [54]. Notably, cellular apoptosis is one of the leading causes of podocyte and renal tubular epithelial cell defects and has a crucial role in DN pathogenesis. Although some reports have shown that several drugs slow the progression of DN, it is difficult to repair a damaged kidney. In recent years, many studies have demonstrated that stem cell transplantation is effective and safe for slowing the development of DN via the regeneration of glomerular tissue $[4,16]$. However, transplanted stem cells seem to remain in an oxidative environment, and oxidative stress induces apoptosis and cell cycle arrest, which reduce transplantation efficiency [37]. Thus, improving the viability of transplanted cells is the key to successful stem cell-based therapy. In the present study, we found that high glucose treatment triggered cellular apoptosis in AFSCs via inhibiting SIRT3 expression. The reintroduction of SIRT3 into AFSCs reversed cellular viability under high glucose stress. Similarly, careful studies from several researchers have confirmed that SIRT3 activation preserves the mononuclear cells mobility [55], protects adipose mesenchymal stem cells against oxidative stress [56], reduces human mesenchymal stem cells senescence by maintaining mitochondrial ROS homeostasis [57], inhibits neural stem cells death [58], promotes bone marrow cell-mediated angiogenesis in post-myocardial infarction [59]. These evidences demonstrate that SIRT3 is the potential target for enhancing stem cell viability and function. More importantly, several researches have illustrated that SIRT3 activation is also important to maintain the kidney function. SIRT3 overexpression improves whole body glucose homeostasis [60], ameliorates the early renal damage induced by a high-fat diet [61], prevents angiotensin II-induced renal tubular epithelial-mesenchymal transition [62], attenuates acute kidney injury via 


\section{Cellular Physiology Cell Physiol Biochem 2018;46:1508-1524 \begin{tabular}{ll|l} 
and Biochemistry $10.1159 / 000489194$ & $\begin{array}{l}\text { Dublished online: April 24, } 2018 \\
\text { www.karger.com/cpb }\end{array}$ \\
\hline
\end{tabular}}

maintaining mitochondrial function [63], alleviates high glucose-induced apoptosis in renal tubular epithelial cells [64] and protects the fructose-induced renal damage via modifying oxidative stress, fibrosis, lipid metabolism and inflammation [65]. Therefore, the above findings suggest that SIRT3 is a noble protein with numerous roles that are essential in kidney physiology. Interestingly, whether stem cell-based therapy could augment the SIRT3 activity in kidney remains unclear. More researches are needed to support this concept.

At the molecular level, SIRT3 sustains mitochondrial function and structure, finally blocking mitochondrial apoptosis pathways. Furthermore, this beneficial effect is dependent on mitophagy activation. SIRT3 signals to mitophagy, which delivers the damaged mitochondria to lysosome. As a consequence of SIRT3-mediated mitophagy, mitochondrial apoptosis is inhibited, contributing to stem cell survival under high glucose-induced injury. To the best of our knowledge, this is the first study to explore the role of SIRT3-mediated mitophagy in AFSC survival under high glucose stimulation. Previous studies have hinted that mitophagy activity is vital to reduce mitochondrial damage and sustain the cellular energy metabolism. In response to cardiac ischemia reperfusion, mitophagy activation provides beneficial effects on cardiomyocytes survival [43]. Similarly, high fat-induced liver death could be abrogated via mitophagy activation [21]. Regarding stem cell, mitophagy activation sustains hematopoietic stem cell self-renewal [66], delays induced pluripotent stem cell senescence [67] and enhances the therapeutic potential of umbilical cord bloodderived human mesenchymal stem cell [68]. These findings identify mitophagy activation as a novel target for control of stem cell viability.

In animal experiments, compared to normal AFSCs, we demonstrated that SIRT3overexpressing AFSCs engraftment further reduced diabetic kidney damage. This information indicated that SIRT3-modified AFSCs may be more powerful than unmodified AFSCs for treating diabetic nephropathy. Functional studies have demonstrated that SIRT3-modified AFSCs engraftment reduced glomerular cell apoptosis and inhibited renal interstitial fibrosis. Furthermore, the mechanism by which stem cell engraftment reduces cellular apoptosis and fibrosis has been explored by several studies $[69,70]$. In conclusion, we explored the effectiveness of SIRT3-modified AFSCs in treating diabetic nephropathy. SIRT3 promotes AFSCs survival via mitophagy activation, leading to improved renal function. Our results provide a new understanding about the protective effects of SIRT3 on AFSCs and offer a new strategy for promoting the therapeutic efficacy of AFSCs in diabetic nephropathy.

\section{Disclosure Statement}

The authors have declared that they have no conflicts of interest.

\section{References}

1 Lu CC, Ma KL, Ruan XZ, Liu BC: The emerging roles of microparticles in diabetic nephropathy. Int J Biol Sci 2017;13:1118-1125.

-2 Haller H, Ji L, Stahl K, Bertram A, Menne J: Molecular mechanisms and treatment strategies in diabetic nephropathy: new avenues for calcium dobesilate-free radical scavenger and growth factor inhibition. Biomed Res Int 2017;2017:1909258.

3 Azushima K, Gurley SB, Coffman TM: Modelling diabetic nephropathy in mice. Nat Rev Nephrol 2018;14:48-56.

4 Jiang Y, Zhang W, Xu S, Lin H, Sui W, Liu H, Peng L, Fang Q, Chen L, Lou J: Transplantation of human fetal pancreatic progenitor cells ameliorates renal injury in streptozotocin-induced diabetic nephropathy. J Transl Med 2017;15:147.

-5 Paulini J, Higuti E, Bastos RM, Gomes SA, Rangel EB: Mesenchymal stem cells as therapeutic candidates for halting the progression of diabetic nephropathy. Stem Cells Int 2016;2016:9521629.

6 Baban B, Liu JY, Payne S, Abebe W, Yu JC, Mozaffari MS: Status of stem cells in diabetic nephropathy: predictive and preventive potentials. EPMA J 2016;7:21. 


\section{Cellular Physiology Cell Physiol Biochem 2018;46:1508-1524 \begin{tabular}{ll|l} 
and Biochemistry Published onlIne: AprI 24, 2018 & $\begin{array}{l}\text { (c) } 2018 \text { The Author(s). Published by S. Karger AG, Basel } \\
\text { www.karger.com/cpb }\end{array}$
\end{tabular}}

7 Nagaishi K, Mizue Y, Chikenji T, Otani M, Nakano M, Konari N, Fujimiya M: Mesenchymal stem cell therapy ameliorates diabetic nephropathy via the paracrine effect of renal trophic factors including exosomes. Sci Rep 2016;6:34842.

-8 Liu Y, Tang SC: Recent progress in stem cell therapy for diabetic nephropathy. Kidney Dis (Basel) 2016;2:20-27.

-9 Xu Y, Xiang J, Zhao H, Liang H, Huang J, Li Y, Pan J, Zhou H, Zhang X, Wang JH, Liu Z, Wang J: Human amniotic fluid stem cells labeled with up-conversion nanoparticles for imaging-monitored repairing of acute lung injury. Biomaterials 2016;100:91-100.

10 Qin M, Chen R, Li H, Liang H, Xue Q, Li F, Chen Y, Zhang X: Direct reprogramming of human amniotic fluid stem cells by OCT4 and application in repairing of cerebral ischemia damage. Int J Biol Sci 2016;12:558568.

11 Li L, Li S, Cai T, Wang H, Xie X, Liu Z, Zhang Y: The targeted inhibitory effects of human amniotic fluid stem cells carrying CXCR4 promoter and DAL-1 on non-small cell lung carcinoma growth. Gene Ther 2016;23:214-222.

12 Morigi M, De Coppi P: Cell therapy for kidney injury: different options and mechanisms--mesenchymal and amniotic fluid stem cells. Nephron Exp Nephrol 2014;126:59.

-13 Hu SY, Zhang Y, Zhu PJ, Zhou H, Chen YD: Liraglutide directly protects cardiomyocytes against reperfusion injury possibly via modulation of intracellular calcium homeostasis. J Geriatr Cardiol 2017;14:57-66.

14 Feng J, Zhao L, Deng H, Wei M, Li J, Xu K: Immune tolerance of amniotic fluid stem cell-induced rat kidney graft and influences on oxidative stress. Transplant Proc 2013;45:3394-3401.

15 Zhou H, Wang S, Zhu P, Hu S, Chen Y, Ren J: Empagliflozin rescues diabetic myocardial microvascular injury via AMPK-mediated inhibition of mitochondrial fission. Redox Biol 2017;15:335-346.

16 Pan XH, Yang XY, Yao X, Sun XM, Zhu L, Wang JX, Pang RQ Cai XM, Dai JJ, Ruan GP: Bone-marrow mesenchymal stem cell transplantation to treat diabetic nephropathy in tree shrews. Cell Biochem Funct 2014;32:453-463.

17 Abdel Aziz MT, Wassef MA, Ahmed HH, Rashed L, Mahfouz S, Aly MI, Hussein RE, Abdelaziz M: The role of bone marrow derived-mesenchymal stem cells in attenuation of kidney function in rats with diabetic nephropathy. Diabetol Metab Syndr 2014;6:34.

18 Fuhrmann DC, Brune B: Mitochondrial composition and function under the control of hypoxia. Redox Biol 2017;12:208-215.

19 Griffiths HR, Gao D, Pararasa C: Redox regulation in metabolic programming and inflammation. Redox Biol 2017;12:50-57.

-20 Jin Q, Li R, Hu N, Xin T, Zhu P, Hu S, Ma S, Zhu H, Ren J, Zhou H: DUSP1 alleviates cardiac ischemia/ reperfusion injury by suppressing the Mff-required mitochondrial fission and Bnip3-related mitophagy via the JNK pathways. Redox Biol 2018;14:576-587.

21 Zhou H, Du W, Li Y, Shi C, Hu N, Ma S, Wang W, Ren J: Effects of melatonin on fatty liver disease: The role of NR4A1/DNA-PKcs/p53 pathway, mitochondrial fission, and mitophagy. J Pineal Res 2018;64:e12450.

22 Zhou H, Li D, Zhu P, Hu S, Hu N, Ma S, Zhang Y, Han T, Ren J, Cao F, Chen Y: Melatonin suppresses platelet activation and function against cardiac ischemia/reperfusion injury via PPARgamma/FUNDC1/mitophagy pathways. J Pineal Res 2017;63:e12438.

23 Zhai M, Li B, Duan W, Jing L, Zhang B, Zhang M, Yu L, Liu Z, Yu B, Ren K, Gao E, Yang Y, Liang H, Jin Z, Yu S: Melatonin ameliorates myocardial ischemia reperfusion injury through SIRT3-dependent regulation of oxidative stress and apoptosis. J Pineal Res 2017;63:e12419.

24 Zhang M, Lin J, Wang S, Cheng Z, Hu J, Wang T, Man W, Yin T, Guo W, Gao E, Reiter RJ, Wang H, Sun D: Melatonin protects against diabetic cardiomyopathy through Mst1/Sirt3 signaling. J Pineal Res 2017;63:e12418.

25 Han L, Wang H, Li L, Li X, Ge J, Reiter RJ, Wang Q: Melatonin protects against maternal obesity-associated oxidative stress and meiotic defects in oocytes via the SIRT3-SOD2-dependent pathway. J Pineal Res 2017;63:e12431.

-26 Tamura H, Kawamoto M, Sato S, Tamura I, Maekawa R, Taketani T, Aasada H, Takaki E, Nakai A, Reiter RJ, Sugino N: Long-term melatonin treatment delays ovarian aging. J Pineal Res 2017;62:e12381.

-27 Zhou H, Yang J, Xin T, Zhang T, Hu S, Zhou S, Chen G, Chen Y: Exendin-4 enhances the migration of adiposederived stem cells to neonatal rat ventricular cardiomyocyte-derived conditioned medium via the phosphoinositide 3-kinase/Akt-stromal cell-derived factor-1alpha/CXC chemokine receptor 4 pathway. Mol Med Rep 2015;11:4063-4072.

28 de Luxan-Delgado B, Potes Y, Rubio-Gonzalez A, Caballero B, Solano JJ, Fernandez-Fernandez M, Bermudez M, Rodrigues Moreira Guimaraes M, Vega-Naredo I, Boga JA, Coto-Montes A: Melatonin reduces endoplasmic reticulum stress and autophagy in liver of leptin-deficient mice. J Pineal Res 2016;61:108123. 


\section{Cellular Physiology Cell Physiol Biochem 2018;46:1508-1524 \begin{tabular}{ll|l} 
and BiOChemistry Published onlIne: April 24, 2018 & $\begin{array}{l}\text { C } 2018 \text { The Author(s). Published by S. Karger AG, Basel } \\
\text { www.karger.com/cpb }\end{array}$ \\
\hline
\end{tabular}}

Feng et al.: SIRT3 Regulates Diabetic Nephropathy via AFSCs

29 Ho HY, Lin CW, Chien MH, Reiter RJ, Su SC, Hsieh YH, Yang SF: Melatonin suppresses TPA-induced metastasis by downregulating matrix metalloproteinase-9 expression through JNK/SP-1 signaling in nasopharyngeal carcinoma. J Pineal Res 2016;61:479-492.

-30 Smith MR, Vayalil PK, Zhou F, Benavides GA, Beggs RR, Golzarian H, Nijampatnam B, Oliver PG, Smith RA, Murphy MP, Velu SE, Landar A: Mitochondrial thiol modification by a targeted electrophile inhibits metabolism in breast adenocarcinoma cells by inhibiting enzyme activity and protein levels. Redox Biol 2016;8:136-148.

-31 Li M, Pi H, Yang Z, Reiter RJ, Xu S, Chen X, Chen C, Zhang L, Yang M, Li Y, Guo P, Li G, Tu M, Tian L, Xie J, He M, Lu Y, Zhong M, Zhang Y, Yu Z, Zhou Z: Melatonin antagonizes cadmium-induced neurotoxicity by activating the transcription factor EB-dependent autophagy-lysosome machinery in mouse neuroblastoma cells. J Pineal Res 2016;61:353-369.

32 Mailloux RJ, Craig Ayre D, Christian SL: Induction of mitochondrial reactive oxygen species production by GSH mediated S-glutathionylation of 2-oxoglutarate dehydrogenase. Redox Biol 2016;8:285-297.

-33 Xu S, Pi H, Zhang L, Zhang N, Li Y, Zhang H, Tang J, Li H, Feng M, Deng P, Guo P, Tian L, Xie J, He M, Lu Y, Zhong M, Zhang Y, Wang W, Reiter RJ, Yu Z, Zhou Z: Melatonin prevents abnormal mitochondrial dynamics resulting from the neurotoxicity of cadmium by blocking calcium-dependent translocation of Drp1 to the mitochondria. J Pineal Res 2016;60:291-302.

34 Zhu YW, Yan JK, Li JJ, Ou YM, Yang Q: Knockdown of radixin suppresses gastric cancer metastasis in vitro by up-regulation of E-cadherin via NF-kappaB/Snail pathway. Cell Physiol Biochem 2016;39:2509-2521.

-35 Han J, Weisbrod RM, Shao D, Watanabe Y, Yin X, Bachschmid MM, Seta F, Janssen-Heininger YM, Matsui R, Zang M, Hamburg NM, Cohen RA: The redox mechanism for vascular barrier dysfunction associated with metabolic disorders: Glutathionylation of Rac1 in endothelial cells. Redox Biol 2016;9:306-319.

-36 Zhou W, Yu L, Fan J, Wan B, Jiang T, Yin J, Huang Y, Li Q, Yin G, Hu Z: Endogenous parathyroid hormone promotes fracture healing by increasing expression of BMPR2 through cAMP/PKA/CREB pathway in mice. Cell Physiol Biochem 2017;42:551-563.

-37 Zhou H, Yang J, Xin T, Li D, Guo J, Hu S, Zhou S, Zhang T, Zhang Y, Han T, Chen Y: Exendin-4 protects adiposederived mesenchymal stem cells from apoptosis induced by hydrogen peroxide through the PI3K/AktSfrp2 pathways. Free Radic Biol Med 2014;77:363-375.

-38 Zhou H, Li D, Shi C, Xin T, Yang J, Zhou Y, Hu S, Tian F, Wang J, Chen Y: Effects of Exendin-4 on bone marrow mesenchymal stem cell proliferation, migration and apoptosis in vitro. Sci Rep 2015;5:12898.

39 Liu L, Li H, Cui Y, Li R, Meng F, Ye Z, Zhang X: Calcium channel opening rather than the release of ATP causes the apoptosis of osteoblasts induced by overloaded mechanical stimulation. Cell Physiol Biochem 2017;42:441-454.

40 Bhatia M, McGrath KL, Di Trapani G, Charoentong P, Shah F, King MM, Clarke FM, Tonissen KF: The thioredoxin system in breast cancer cell invasion and migration. Redox Biol 2016;8:68-78.

41 Lin YW, Lee LM, Lee WJ, Chu CY, Tan P, Yang YC, Chen WY, Yang SF, Hsiao M, Chien MH: Melatonin inhibits MMP-9 transactivation and renal cell carcinoma metastasis by suppressing Akt-MAPKs pathway and NFkappaB DNA-binding activity. J Pineal Res 2016;60:277-290.

42 Dong X, Fu J, Yin X, Qu C, Yang C, He H, Ni J: Induction of apoptosis in HepaRG cell line by aloe-emodin through generation of reactive oxygen species and the mitochondrial pathway. Cell Physiol Biochem 2017;42:685-696.

43 Zhou H, Zhu P, Guo J, Hu N, Wang S, Li D, Hu S, Ren J, Cao F, Chen Y: Ripk3 induces mitochondrial apoptosis via inhibition of FUNDC1 mitophagy in cardiac IR injury. Redox Biol 2017;13:498-507.

44 Zhou H, Hu S, Jin Q, Shi C, Zhang Y, Zhu P, Ma Q, Tian F, Chen Y: Mff-dependent mitochondrial fission contributes to the pathogenesis of cardiac microvasculature ischemia/reperfusion injury via induction of mROS-mediated cardiolipin oxidation and HK2/VDAC1 disassociation-involved mPTP opening. J Am Heart Assoc 2017;6: e005328.

45 Zhu H, Jin Q, Li Y, Ma Q, Wang J, Li D, Zhou H, Chen Y: Melatonin protected cardiac microvascular endothelial cells against oxidative stress injury via suppression of IP3R- [Ca2+]c/VDAC- $[\mathrm{Ca} 2+] \mathrm{m}$ axis by activation of MAPK/ERK signaling pathway. Cell Stress Chaperones 2017;23: 101-113.

46 Yang HH, Chen Y, Gao CY, Cui ZT, Yao JM: Protective effects of microRNA-126 on human cardiac microvascular endothelial cells against hypoxia/reoxygenation-induced injury and inflammatory response by activating PI3K/Akt/eNOS signaling pathway. Cell Physiol Biochem 2017;42:506-518.

-47 Peleli M, Zollbrecht C, Montenegro MF, Hezel M, Zhong J, Persson EG, Holmdahl R, Weitzberg E, Lundberg JO, Carlstrom M: Enhanced XOR activity in eNOS-deficient mice: Effects on the nitrate-nitrite-NO pathway and ROS homeostasis. Free Radic Biol Med 2016;99:472-484.

48 Mailloux RJ, Treberg JR: Protein S-glutathionlyation links energy metabolism to redox signaling in mitochondria. Redox Biol 2016;8:110-118. 


\section{Cellular Physiology Cell Physiol Biochem 2018;46:1508-1524 \begin{tabular}{ll|l} 
and Biochemistry Published online: April 24, 2018 & $\begin{array}{l}\text { (C) } 2018 \text { The Author(s). Published by S. Karger AG, Basel } \\
\text { www.karger.com/cpb }\end{array}$
\end{tabular}}

Feng et al.: SIRT3 Regulates Diabetic Nephropathy via AFSCs

49 Heppner DE, van der Vliet A: Redox-dependent regulation of epidermal growth factor receptor signaling. Redox Biol 2016;8:24-27.

50 Tan DX, Hardeland R, Back K, Manchester LC, Alatorre-Jimenez MA, Reiter RJ: On the significance of an alternate pathway of melatonin synthesis via 5-methoxytryptamine: comparisons across species. J Pineal Res 2016;61:27-40.

51 Zhang Y, Zhou H, Wu W, Shi C, Hu S, Yin T, Ma Q, Han T, Zhang Y, Tian F, Chen Y: Liraglutide protects cardiac microvascular endothelial cells against hypoxia/reoxygenation injury through the suppression of the SR-Ca(2+)-XO-ROS axis via activation of the GLP-1R/PI3K/Akt/survivin pathways. Free Radic Biol Med 2016;95:278-292.

52 Shi C, Cai Y, Li Y, Li Y, Hu N, Ma S, Hu S, Zhu P, Wang W, Zhou H: Yap promotes hepatocellular carcinoma metastasis and mobilization via governing cofilin/F-actin/lamellipodium axis by regulation of JNK/Bnip3/ SERCA/CaMKII pathways. Redox Biol 2018;14:59-71.

53 Zhou H, Zhang Y, Hu S, Shi C, Zhu P, Ma Q Jin Q, Cao F, Tian F, Chen Y: Melatonin protects cardiac microvasculature against ischemia/reperfusion injury via suppression of mitochondrial fission-VDAC1HK2-mPTP-mitophagy axis. J Pineal Res 2017;63:e12413.

-54 Zhou H, Wang J, Zhu P, Hu S, Ren J: Ripk3 regulates cardiac microvascular reperfusion injury: The role of IP3R-dependent calcium overload, XO-mediated oxidative stress and F-action/filopodia-based cellular migration. Cell Signal 2018;45:12-22.

55 Michalak S, Florczak-Wyspianska J, Rybacka-Mossakowska J, Ambrosius W, Osztynowicz K, Baszczuk A, Kozubski W, Wysocka E: Mitochondrial respiration in intact peripheral blood mononuclear cells and sirtuin 3 activity in patients with movement disorders. Oxid Med Cell Longev 2017;2017:9703574.

56 Chierchia A, Chirico N, Boeri L, Raimondi I, Riva GA, Raimondi MT, Tunesi M, Giordano C, Forloni G, Albani D: Secretome released from hydrogel-embedded adipose mesenchymal stem cells protects against the Parkinson's disease related toxin 6-hydroxydopamine. Eur J Pharm Biopharm 2017;121:113-120.

-57 Jung YH, Lee HJ, Kim JS, Lee SJ, Han HJ: EphB2 signaling-mediated Sirt3 expression reduces MSC senescence by maintaining mitochondrial ROS homeostasis. Free Radic Biol Med 2017;110:368-380.

-58 Jiang DQ, Wang Y, Li MX, Ma YJ, Wang Y: SIRT3 in neural stem cells attenuates microglia activation-induced oxidative stress injury through mitochondrial pathway. Front Cell Neurosci 2017;11:7.

-59 Zeng H, Li L, Chen JX: Loss of Sirt3 limits bone marrow cell-mediated angiogenesis and cardiac repair in post-myocardial infarction. PLoS One 2014;9:e107011.

60 Ramachandran D, Clara R, Fedele S, Hu J, Lackzo E, Huang JY, Verdin E, Langhans W, Mansouri A: Intestinal SIRT3 overexpression in mice improves whole body glucose homeostasis independent of body weight. Mol Metab 2017;6:1264-1273.

61 Yi W, Xie X, Du M, Bu Y, Wu N, Yang H, Tian C, Xu F, Xiang S, Zhang P, Chen Z, Zuo X, Ying C: Green tea polyphenols ameliorate the early renal damage induced by a high-fat diet via ketogenesis/SIRT3 pathway. Oxid Med Cell Longev 2017;2017:9032792.

-62 He P, Li Z, Yue Z, Gao H, Feng G, Wang P, Huang Y, Luo W, Hong H, Liang L, Chen S, Liu P: SIRT3 prevents angiotensin II-induced renal tubular epithelial-mesenchymal transition by ameliorating oxidative stress and mitochondrial dysfunction. Mol Cell Endocrinol 2018;460:1-13.

63 Li Y, Ye Z, Lai W, Rao J, Huang W, Zhang X, Yao Z, Lou T: Activation of sirtuin 3 by silybin attenuates mitochondrial dysfunction in cisplatin-induced acute kidney injury. Front Pharmacol 2017;8:178.

64 Jiao X, Li Y, Zhang T, Liu M, Chi Y: Role of Sirtuin3 in high glucose-induced apoptosis in renal tubular epithelial cells. Biochem Biophys Res Commun 2016;480:387-393.

65 Zhou H, Ma Q Zhu P, Ren J, Reiter RJ, Chen Y: Protective role of melatonin in cardiac ischemia-reperfusion injury: from pathogenesis to targeted therapy. J Pineal Res 2018;64:e12471.

66 Jin G, Xu C, Zhang X, Long J, Rezaeian AH, Liu C, Furth ME, Kridel S, Pasche B, Bian XW, Lin HK: Atad3a suppresses Pink1-dependent mitophagy to maintain homeostasis of hematopoietic progenitor cells. Nat Immunol 2018;19:29-40.

67 Jimenez-Moreno N, Stathakos P, Caldwell MA, Lane JD: Induced pluripotent stem cell neuronal models for the study of autophagy pathways in human neurodegenerative disease. Cells 2017;6:e24.

68 Lee HJ, Jung YH, Choi GE, Ko SH, Lee SJ, Lee SH, Han HJ: BNIP3 induction by hypoxia stimulates FASNdependent free fatty acid production enhancing therapeutic potential of umbilical cord blood-derived human mesenchymal stem cells. Redox Biol 2017;13:426-443.

69 Ibrahim ME, Bana EE, El-Kerdasy HI: Role of bone marrow derived mesenchymal stem cells and the protective effect of silymarin in cisplatin-induced acute renal failure in rats. Am J Med Sci 2018;355:76-83.

-70 Rivera-Valdes JJ, Garcia-Banuelos J, Salazar-Montes A, Garcia-Benavides L, Rosales-Dominguez A, Armendariz-Borunda J, Sandoval-Rodriguez A: Human adipose derived stem cells regress fibrosis in a chronic renal fibrotic model induced by adenine. PLoS One 2017;12:e0187907. 